\title{
ANAESTHETIC MACHINE PIPELINE INLET PRESSURE GAUGES DO NOT ALWAYS MEASURE PIPELINE PRESSURE
}

\author{
Douglas B. Craig and John Longmuir
}

\begin{abstract}
Some anaesthetic gas machines have pipeline inlet pressure gauges which indicate the higher of either pipeline pressure, or machine circuit pressure (the pressure distal to the pressure reducing valve, and proximal to the flowmeter control valve). Failure by the operator to appreciate this feature may in specific circumstances lead to a delayed appreciation of pipeline malfunction or disconnection. The Canadian Standards Association Z168.3-M1980 Anaesthetic Gas Machine Standard requires pipeline inlet gauges which measure only pipeline (hose) pressure. Existing machines should be modified to accommodate this requirement.
\end{abstract}

IT IS GENERALLY ASSUMED, that on those anaesthetic gas machines which have pressure gauges for both the cylinder yokes and pipeline inlets, the pipeline gauges always indicate pipeline pressure. This assumption is in error for some models of anaesthetic machines. Failure of the operator to appreciate the error of this assumption could, under specific circumstances, be hazardous.

The pipeline inlet pressure gauges on Boyle Model $\mathrm{M}$ and Boyle International units indicate the higher of either pipeline pressure, or machine circuit pressure (the pressure distal to the pressure reducing valve, and proximal to the flowmeter control valve). This means that during operation of the unit from a cylinder source, without connection to the pipeline, the pipeline inlet gauge indicates the reduced gas pressure, while the cylinder yoke gauge indicates the cylinder pressure.

The potential hazard arises from the failure of the operator to appreciate that the pipeline inlet gauge can indicate either of the two pressures. With the cylinder open but the pipeline not connected or not pressurized, the operator may incorrectly conclude that the unit is operating from the pipeline source. Only when the cylinder empties will the pipeline inlet gauge indicate a loss of pressure. The cylinder, normally reserved for emergency situations, such as interruption of pipeline flow, will now be empty.

The recently published Canadian' and

Douglas B. Craig, M.D., F.R.C.P.(C), Professor, Department of Anaesthesia, University of Manitoba; John Longmuir, Special Anaesthetic Technologist, Health Sciences Centre. Department of Anaesthesia, Health Sciences Centre, 700 William Ave., Winnipeg, Manitoba, R3E 0Z3.
American ${ }^{2}$ anaesthetic gas machine standards address the problem outlined above. Item 6.3 (pipeline pressure gauges) of the Canadian Standard states: "Gases supplied by pipeline from central supplies at reduced pressures shall be monitored by pressure gauges. These gauges shall indicate the pressure of the gas in the pipeline hoses when attached to the machine." In view of this requirement, it is clearly not acceptable to have the pipeline inlet gauge indicate any other pressure but the pressure in the pipeline hoses.

Item 6.1 .3 of the American Standard states: "Gas supplied by pipeline from central supplies at reduced pressures should be monitored by pressure gauges also. These gauges shall indicate the pressure of the gases in the pipeline hoses when the hoses are attached to the anesthesia machine."

Since "shall" indicates a mandatory component of the standard and "should" indicates a recommendation which is optional, some anaesthetic gas machines which meet the mandatory requirements of the American Standard may not have pipeline inlet gauges. However, should these gauges be supplied, it is clear that they must only measure pipeline pressure.

While the two Boyle models noted (M and International) have the features described, other Boyle models (10, K, MS and Mini-Boyle) do not. When pipeline inlet pressure gauges are present on these units, they only indicate pipeline (hose) pressure. We are unable to comment on whether apparatus of different manufacturers have similar features. We would encourage users of all types of anaesthetic gas machines to be fully aware of the operating features of their particular unit. We feel that the upgrading of existing anaesthetic 
machines in response to the Canadian Standard should include accommodation of item 6.3 as noted above. A Province of Manitoba anaesthetic gas machine upgrading program ${ }^{3}$ which included accommodation of item 6.3 was completed in June 1980 on Boyle models $M$ and International units. The non-return valve incorporated in the pipeline inlet assembly has been relocated, with the result that the pipeline inlet gauges now measure pipeline pressure, and only pipeline pressure.
REFERENCES

1. CSA Standard Z168.3-M1980. Continuous fiow inhalation anaesthetic apparatus (anaesthetic machines) for medical use. Canadian Standards Association, Rexdale, Ontario (1980).

2. ANSI Standard Z79.8-1979. Minimum performance and safety requirements for components and systems of continuous flow anesthesia machines for human use. American National Standards Institute, New York (1979).

3. Implementation of Canadian Standards Association Z168.3M1980. Anaesthetic gas machine standard: the Manitoba experience. Canad. Anaes. Soc. J. 27: 504-509 (1980).

RÉSUMÉ

Les conduites d'alimentation de certains appareils d'anesthésie sont munies de manomètres qui mesurent la pression dans la canalisation même de l'appareil ou dans le circuit anesthésique (la pression mesurée en aval du manodétendeur et en amonı du débitmètre). $\mathrm{Si}$ on ne tient pas compte de cette caractéristique, on peut faire une erreur d'appréciation et se retrouver dars l'incapacité de distinguer un mauvais fonctionnement de la conduite d'un débranchement accidentel. La norme Z168.3-M1980 de Standard Canada qui règlemente les appareils d'ancsthésie exige la présence d'un manomètre exclusif pour la pression des canalisations. Les appareils en usage présentement devraient être modifiés pour répondre à cette exigence. 